\title{
Detection of antibodies against glucose 6-phosphate isomerase in synovial fluid of rheumatoid arthritis using surface plasmon resonance (BIAcore)
}

\author{
Ji-Yeon Kim ${ }^{1}$, Mi-Hong Lee ${ }^{1}$, \\ Kyung-In Jung ${ }^{1}$, Hye Young $\mathrm{Na}^{1}$, \\ Hoon-Suk Cha ${ }^{2}$, Eun-Mi Koh ${ }^{2}$, \\ and Tae Jin $\mathrm{Kim}^{1,3}$ \\ ${ }^{1}$ Department of Pathology and \\ Center for Molecular Medicine \\ Samsung Biomedical Research Institute \\ School of Medicine, Sungkyunkwan University \\ Suwon 440-746, Korea \\ ${ }^{2}$ Department of Medicine, Samsung Medical Center \\ School of Medicine, Sungkyunkwan University \\ Seoul 135-710, Korea \\ ${ }^{3}$ Corresponding author: Tel, 82-31-299-6161; \\ Fax, 82-31-299-6179; E-mail, tjkim@med.skku.ac.kr \\ Accepted 16 July 2003
}

Abbreviations: GPI, glucose 6-phosphate isomerase; HBS, HEPESbuffered saline; NHS, n-hydroxysuccinimide; RA, rheumatoid arthritis; RF, rheumatoid factor; $O A$, osteoarthritis; $R U$, resonance units; SPR, surface plasmon resonance

\begin{abstract}
We have used a surface plasmon resonance biosensor (SPR, BIACORE 2000) to detect antibodies against glucose 6-phosphate isomerase (GPI) in synovial fluids of rheumatoid arthritis (RA) and osteoarthritis (OA). Recombinant human GPI proteins fused with or without NusA were expressed in $E$. coli, purified to homogeneity and immobilized in flow cells of CM5 sensor chips. The flow cells immobilized with NusA protein or bovine serum albumin were used to monitor non-specific binding. Synovial fluid samples from RA patients showed a significantly higher level of binding to recombinant GPI proteins than samples from OA patients. Proteins which bound to the recombinant GPI proteins were confirmed to be immunoglobulin through the administration of anti-human immunoglobulin. NusA fusion protein was excellent for this assay because of a low background binding activity in the SPR analysis and its advantage of increased solubility in recombinant protein production. These results suggested a useful utilization of recombi-
\end{abstract}

nant NusA-GPI fusion protein for the detection of autoantibodies against GPI in RA patients.

Keywords: autoimmune disease; biosensing techniques; glucose 6-phosphate isomerase; rheumatoid arthritis; Serology

\section{Introduction}

A hallmark of autoimmune disease is the production of high-affinity autoantibodies. Although some autoantibodies are primarily involved in tissue damage and pathogenesis, most autoantibodies do not have proven pathogenetic roles. Nevertheless, autoantibody responses for certain antigens are used as important tools for accurate diagnosis, classificiation and prognostication (Lernmark, 2001). More importantly, a comprehensive profiling of autoantibodies may provide insights into the pathogenesis of autoimmunity (Hueber et al., 2002; Robinson et al., 2002), since the number of target autoantigens is not diverse, but limited depending on structural properties, microenvironmental concentrations, localizations, and so on (Plotz, 2003).

Rheumatoid arthritis (RA) is a common systemic autoimmune disease characterized by inflammation of the synovial membrane of diarthrodial joints. It is diagnosed by signs and symptoms of chronic erosive inflammation of diarthrodial joints. Autoantibodies of various type are known to be detected in RA patients (van Boekel et al., 2002). The most representative antibody is the 'rheumatoid factor' (RF) which was first described about 75 years ago. However, the RF antibody is present only in about $75 \%$ of RA patients. Furthermore, RF is also found in patients with other autoimmune diseases such as Sjögren's syndrome and infectious diseases and in healthy populations (3-5\%). Despite its relatively low specificity, the presence of RF is widely used as a diagnostic marker for RA (van Boekel et al., 2002). Recently, autoantibody against glucose 6-phosphate isomerase (GPI) was shown to be present in the serum of RA patients (Schaller et al., 2001). GPI is an essential enzyme in all types of cells, catalyzing the interconversion of fructose-6-phosphate and glucose-6-phosphate. Normally, the human GPI protein consists of 558 amino acids and is present in the form of a dimeric enzyme (Sun et al., 1990; Xu et al., 1995). Even though it is a cytoplasmic enzyme, its expression was noted extra- 
cellularly in joint linings (Matsumoto et al., 2002; Wipke et al., 2002) and it is genetically identical to neuroleukin, a growth factor which promotes motor neuron regeneration in vivo, survival of peripheral and central neurons in vitro, and affects $B$ cell immunoglobulin synthesis (Gurney et al., 1986; Chaput et al., 1988; Faik et al., 1988; Haga et al., 2000; Amraei and Nabi, 2002). In mouse models, injection of antiGPI antibody initiated a RA-like autoimmune disease (Mandik-Nayak et al., 2002) and thus anti-GPI B cell response seems to be important for triggering of the autoimmune disease.

In this study, we produced a recombinant fusion NusA-GPI protein and tested its utilization in the detection of antibodies against GPI protein. To this end, we immobilized the purified recombinant GPI protein produced from E.coli on the CM5 sensor chips and measured the relative amounts of antibodies present in synovial fluid samples from patients of RA and osteoarthritis (OA) using the surface plasmon resonance (SPR) biosensor.

\section{Materials and Methods}

\section{Construction of GPI expression constructs}

The E. coli expression vector that directed the expression of human GPI cDNA was constructed as schematically shown in Figure 1. Fragment 1 (35-740 bp of GPI) and fragment 2 (657-1677 bp of GPI) were obtained by RT-PCR with $0.25 \mu \mathrm{g}$ of human testis total RNA (Clontech, CA). cDNA synthesis by Powerscript reverse transcriptase (Clontech) was followed by amplification by Pfu DNA polymerase (Stratagene, CA). The PCR reaction was carried out in PTC-100 ${ }^{T M}$ programmable thermal controler (MJ Research, Inc., $\mathrm{MA})$ and the samples were subjected to $1 \mathrm{~min}$ denaturation at $94^{\circ} \mathrm{C}, 1 \mathrm{~min}$ annealing at $52^{\circ} \mathrm{C}$ and $2 \mathrm{~min}$ elongation at $72^{\circ} \mathrm{C}$ for 30 cycles. The obtained fragment $1 \mathrm{PCR}$ product was digested with $\mathrm{Kpnl}$ and $\mathrm{BamHI}$, and the fragment 2 was digested with $\mathrm{BamHI}$ and Notl, and subcloned into the Kpnl and Notl sites of pBluescript II KS(-) (Stratagene). For E. coli expression vector, two complementary oligonucleotides (5'AATTCATGGCCGCTCTCACCCGGGACCCCCAGTT CCAGAAGCTGCAGCAATGGTAC-3' and 5'-CATTGCTGCAGCTTCTGGAACTGGGGGTCCCGGGTGAGAGCGGCCATG-3') corresponding 1-47 bp and the Kpnl-Notl fragment were subcloned into pET28a and pET43.1a vector (Novagen, WI). The construct was confirmed by restriction enzyme digestion and DNA sequencing.

\section{Overexpression and one-step purification of recombinant $\mathrm{GPI}$ and NusA-GPI proteins}

The pET28a-GPI and pET43.1a-GPI expression con-

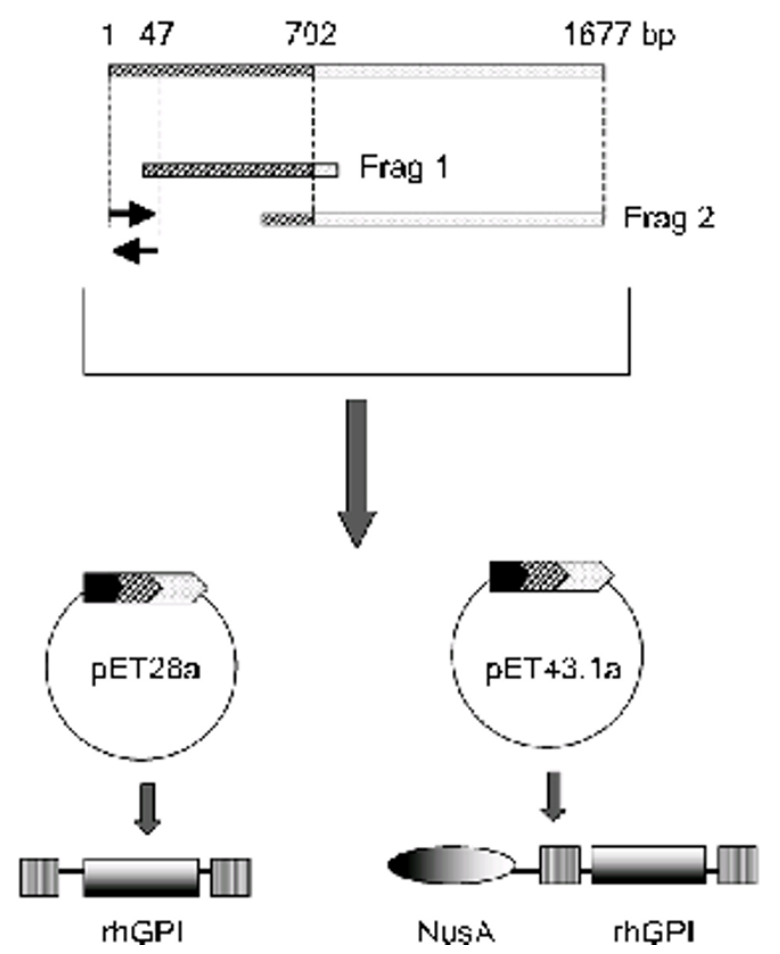

Figure 1. Cloning scheme of recombinant GPI expression constructs. GPI expression construct was made through several steps. Firstly, Fragment 1 (35-740 bp of GPI) and fragment 2 (657-1677bp of GPI) were obtained by RT-PCR. The obtained fragment 1 PCR product was digested with $\mathrm{Kpnl}$ and $\mathrm{BamHI}$, and the fragment 2 was digested with BamHI and Notl, and subcloned into the Kpnl and Notl sites of pBluescript II. Two complementary oligonucleotides corresponding to $1-47 \mathrm{bp}$, and the Kpnl-Notl fragment were subcloned into pET28a and pET43.1a vector. GPI and NusA-GPI proteins were overexpressed in E. coli strains containing pET28a-GPI and pET43.1a-GPI, respectively.

structs were freshly transformed into BL21-Codonplus (DE3)-RIL (Novagen). One liter of Luria broth containing appropriate antibiotics and chloramphenicol (34 $\mu \mathrm{g} / \mathrm{ml}$ ) was inoculated with $10 \mathrm{ml}$ overnight growth of E. coli tansformants bearing pET28a-GPI/or pET43. $1 \mathrm{a}-\mathrm{GPI}$ and incubated at $37^{\circ} \mathrm{C}$ with vigorously shaking for $3 \mathrm{~h}$ until an $\mathrm{A}_{600}$ of 0.7-0.8 was obtained. Then $0.4 \mathrm{mM}$ IPTG was added and incubation was continued for $3 \mathrm{~h}$. Cells were harvested by centrifugation at $7,000 \mathrm{~g}$ for $5 \mathrm{~min}$ and the cell pellets were frozen at $-70^{\circ} \mathrm{C}$.

For GPI or NusA-GPI protein, the cell pellets were resuspended in $100 \mathrm{ml}$ of $20 \mathrm{mM} \mathrm{Tris} / \mathrm{HCl}(\mathrm{pH} 8.0)$ containing $300 \mathrm{mM} \mathrm{NaCl}, 100 \mathrm{mM}$ imidazole and $20 \%$ sucrose, and then lysed by sonication at $4^{\circ} \mathrm{C}$. The crude extract was clarified by centrifugation at 15,000 $g$ for $1 \mathrm{~h}$. One-step of Ni-NTA (Qiagen, Germany) affinity chromatography was performed in the purification of recombinant GPI protein. The column was connected to an AKTA ${ }^{\text {FPLC TM }}$ (Amersham Pharmacia, Sweden). The supernatant containing GPI protein was 
loaded onto pre-equilibrated Ni-NTA affinity column and washed with $100 \mathrm{ml}$ of same buffer without sucrose. Then GPI fusion proteins were eluted with a linear gradient of $100-350 \mathrm{mM}$ (for GPI) or 50-200 $\mathrm{mM}$ (for Nus-GPI) imidazole in same buffer at a flow rate of $2 \mathrm{ml} / \mathrm{min}$, and $10 \mathrm{ml}$ of fractions were collected. The GPI fractions were confirmed by SDS-PAGE and were pooled.

\section{Determination of molecular weight of recombinant GPI and NusA-GPI proteins}

The molecular weight of the purified recombinant GPI proteins was determined by gel filtration chromatography. The purified GPI protein was loaded on a Hi-Load 16/60 Superdex 200 pg column which is pre-equilibrated in $20 \mathrm{mM}$ Tris $/ \mathrm{HCl}(\mathrm{pH} \mathrm{8.0)}, 1 \mathrm{mM}$ EDTA, $1 \mathrm{mM}$ DTT, $0.1 \mathrm{mM}$ PMSF and $300 \mathrm{mM} \mathrm{NaCl}$. The column was calibrated with horse spleen ferritin (440 kDa), bovine liver catalase $(232 \mathrm{kDa})$, rabbit muscle aldolase (158 kDa), BSA (67 kDa), hen egg ovalbumin (43 kDa), bovine pancreas chymotrypsinogen $A(25 \mathrm{kDa})$ and bovine pancreas ribonuclease A (13 kDa) (Amersham Pharmacia).

\section{Patients' synovial fluid}

The experimental protocol was approved by the local ethics committee and a signed consent form was obtained from each patient. Synovial fluids of the knee joints were obtained from five patients with RA and five with OA. Diagnosis of each disease was defined according to the proposed criteria (Altman et al., 1986; Arnett et al., 1988).
$A$

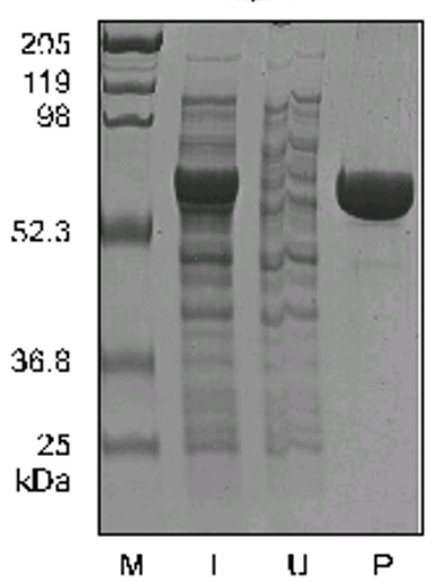

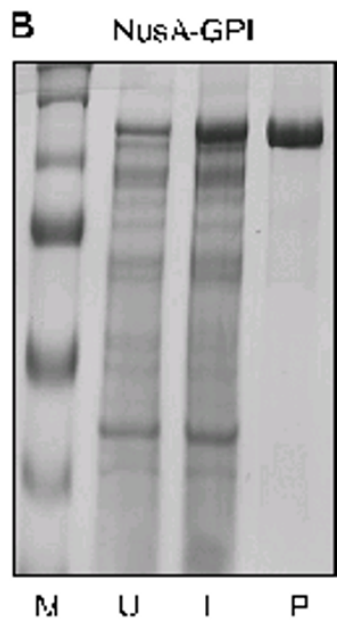

Figure 2. SDS-PAGE analysis of purified GPI (A) and NusA-GPI (B) proteins. MW markers (M); overexpression of GPI or NusA-GPI after $22 \mathrm{~h}$ of cell growth in LB medium with ( $\mathrm{l}$; induced) or without (U; uninduced) IPTG induction; purified GPI or Nus-GPI protein (P).

\section{Surface plasmon resonance (SPR) analysis}

Sets of binding experiments were performed using the BIAcore 2000 Upgrade (BIAcore AB, Sweden) and optical SPR biosensor system as previously described (Gil et al., 2002). Purified GPI recombinant proteins were covalently coupled to sensor chips CM5 using standard amine coupling chemistry. Briefly, the carboxylated dextran matrix was activated by injecting a mixture of $50 \mathrm{mM} \mathrm{N}$-hydroxysuccinimide (NHS) and $0.2 \mathrm{M} \quad \mathrm{N}$-ethyl-N'-(3-diethylaminopropyl)carbodiimide $(1: 1)$ for a period of $7 \mathrm{~min}$. GPI fusion protein $(50$ $\mu \mathrm{g} / \mathrm{ml}$ in $10 \mathrm{mM}$ sodium acetate buffer, $\mathrm{pH} 4.0$ ) was then injected, followed by $1 \mathrm{M}$ ethanolamine hydrochloride $(\mathrm{pH}$ 8.5) to block the remaining NHS ester groups. A running and dilution buffer [10 mM HEPES$\mathrm{NaOH}$ ( $\mathrm{pH} 7.4$ ), $150 \mathrm{mM} \mathrm{NaCl}, 1 \mathrm{mM}$ EDTA] was used in all binding experiments and a pulse of 3.5 $\mathrm{mM} \mathrm{NaOH}$ for regenerations. Biosensor surfaces were coupled to the final resonance values of approximately $4500 \mathrm{RU}$. Nonspecific binding to the matrix was eliminated by subtracting the signal obtained on a control surface (activated caboxymethyldextran saturated with BSA). All specimens were diluted 1:100 with the HEPES running buffer. Samples were injected at $10 \mu \mathrm{l} / \mathrm{min}$ for $3 \mathrm{~min}$ using multichannel detection. Samples were exposed to both active and control surfaces. The interaction curves of different patient's fluids to immobilized GPI on the sensor chip were monitored as a separate sensorgram. The response was measured in resonance units (RU). $1 \mathrm{RU}$ corresponded to surface mass change of $1 \mathrm{pg}$ protein $/ \mathrm{mm}^{2}$.

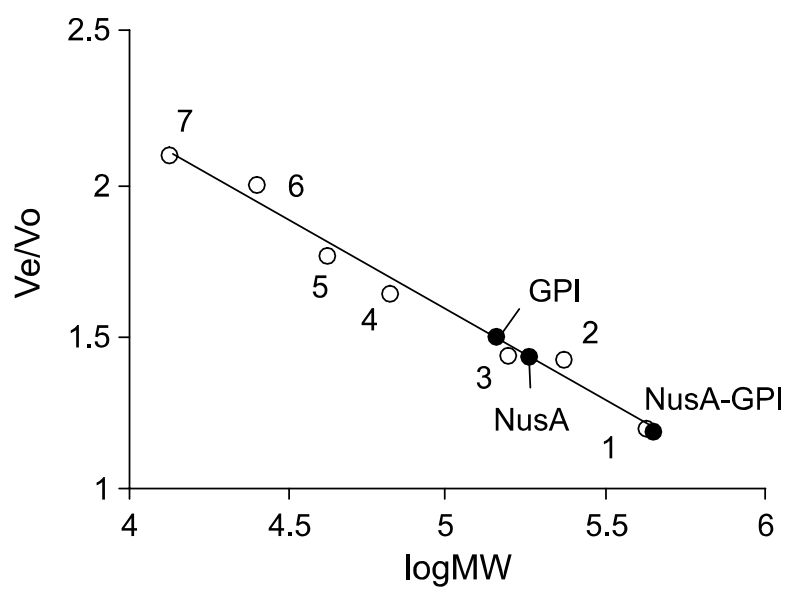

Figure 3. Estimation of the molecular weights of the purified GPI and NusA-GPI. The molecular weights of GPI and NusA-GPI were measured by gel-filtration chromatography on a Hi-Load 16/60 Superdex $200 \mathrm{pg}$ column. Molecular weight markers used were (1) horse spleen ferritin $(440 \mathrm{kDa}),(2)$ bovine liver catalase $(232 \mathrm{kDa}),(3)$ rabbit muscle aldolase (158 kDa), (4) BSA (67 kDa), (5) hen egg ovalbumin $(43 \mathrm{kDa}),(6)$ bovine pancreas chymotrypsinogen $\mathrm{A}(25 \mathrm{kDa})$, and $(7)$ bovine paccreas ribonuclease $A(13 \mathrm{kDa})$. 


\section{Results}

\section{Cloning, overexpression, and purification of recombinant GPI and NusA-GPI proteins}

The recombinant GPI protein was overexpressed in $E$. coli and purified to homogeneity by a single step purification protocol as described in Materials and Methods and analyzed by SDS-PAGE with Coomasie blue staining. The SDS-PAGE analysis revealed a single band of protein with molecular weight of about $65 \mathrm{kDa}$, which corresponds to the calculated weight of GPI (Figure 2A). About $120 \mathrm{mg}$ of GPI protein with $99 \%$ of purity were obtained from 1 liter of cell culture. In gel filtration chromatography, the MW of GPI protein was estimated to be $130 \mathrm{kDa}$ (Figure 3), which suggested that GPI protein was present as homodimers in the solution as previously described
(Sun et al., 1999).

NusA-GPI fusion protein migrated as a band of about $127 \mathrm{kDa}$ on SDS-PAGE (Figure 2B) and was eluted as a protein of molecular weight $515 \mathrm{kDa}$ in gel filtration chromatography (Figure 3). Therefore, NusA-GPI was considered to be present as homotetramers.

\section{Detection of anti-GPI antibodies present in synovial fluid samples from patients of rheumatoid arthritis and osteoarthritis}

Next we asked whether the recombinant GPI or NusA-GPI protein could be used for the detection of anti-GPI Abs present in RA patients. Synovial joint fluids from $R A$ and $O A$ patients were used to test the presence of anti-GPI Abs in joint fluids by the SPR
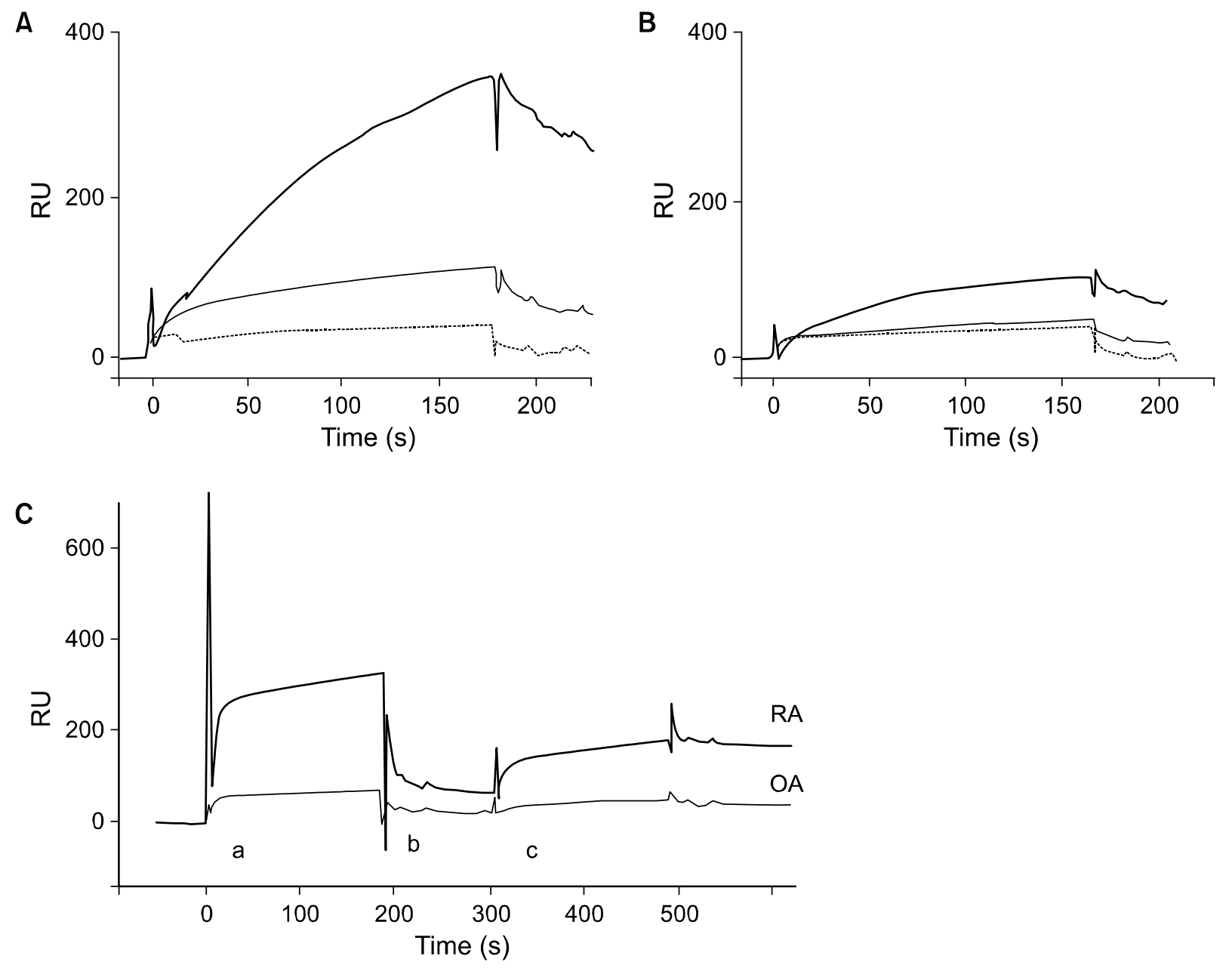

Figure 4. Representative sensograms of the joint fluids from RA (A) and $O A(B)$ patients and use of secondary antibody for identification of anti-GPI antibody (C). 1:100 diluted joint fluids were injected onto the CM5 sensor chips immobilized with NusA, GPI, and NusA-GPI followed by the running buffer. Specific binding signals were obtained by subtraction of nonspecific signals from binding on BSA-immobilized flow cells. In (C), injection of joint fluids from RA and OA patients (as indicated) into Nus-GPI-coated CM5 flow cells (indicated as a) was followed by washing with running buffer (b) and introduction of $0.1 \mathrm{mg} / \mathrm{ml}$ solution of goat anti-human immunoglobulin (Zymed Laboratories) (c). 
Table 1. Comparison of peak RU values from joint fluids from $5 \mathrm{RA}$ and $5 \mathrm{OA}$ patients on the CM5 chips immobilized with NusA-GPI and GPI fusion proteins.

\begin{tabular}{|c|c|c|c|c|c|}
\hline \multirow{2}{*}{ Test sample } & \multirow{2}{*}{ Age/sex } & \multicolumn{2}{|c|}{$\mathrm{RU}$} & \multirow{2}{*}{$\mathrm{RF}$} & \multirow{2}{*}{$\begin{array}{c}\text { ESR } \\
(\mathrm{mm} / \mathrm{h})\end{array}$} \\
\hline & & Nus-GPI & GPI & & \\
\hline RA1 & $\mathrm{M} / 64$ & 302 & 121.5 & - & 81 \\
\hline RA2 & $\mathrm{F} / 72$ & 230.8 & 97.2 & + & 53 \\
\hline RA3 & $\mathrm{F} / 52$ & 229.7 & 94.2 & + & 57 \\
\hline RA4 & $\mathrm{F} / 54$ & 158.5 & 102.6 & + & 28 \\
\hline RA5 & $F / 66$ & 121.1 & 105.9 & + & 20 \\
\hline OA1 & $F / 65$ & 73 & 35.2 & ND & ND \\
\hline $\mathrm{OA} 2$ & $\mathrm{~F} / 53$ & 64.9 & 31.9 & ND & ND \\
\hline OA3 & $\mathrm{F} / 60$ & 61.9 & 40.6 & ND & ND \\
\hline OA4 & $F / 61$ & 55 & 40.7 & ND & ND \\
\hline OA5 & $F / 68$ & 52 & 45.8 & ND & ND \\
\hline
\end{tabular}

RU, resonance unit; RF, rheumatoid factor; ESR, erythrocyte sedimentation rate; ND, not done. 1:100 diluted joint fluids were injected onto the CM5 sensor chips followed by the running buffer. Specific binding signals were obtained by subtraction of nonspecific signals from binding on BSA-immobilized flow cells. Laboratory test results were shown.

analysis. The joint fluids diluted 1:100 in the running buffer were used as the mobile reactants, and the recombinant GPI or NusA-GPI proteins were immobilized on flow cell 3 . The amounts of immobilized GPI and Nus-GPI fusion proteins were 4,500 RU for both GPI and NusA-GPI. The surface of reference cell, flow cell 1, was coated with 6,000 RU of an unrelated protein, BSA. $4,500 \mathrm{RU}$ of NusA protein was immobilized in flow cell 2 to screen the presence of any proteins which bind NusA protein and would inhibit the accurate assay for anti-GPI $A b$. The representative sensograms in Figure $4 \mathrm{~A}$ and $4 \mathrm{~B}$ show the difference in the magnitude of the kinetic signals generated by the binding of the joint fluids to indicated immobilized proteins (NusA-GPI, GPI, and NusA) and to BSA (flow cell 1). There was very small binding activity of joint fluids to NusA in both RA and OA samples. Typically, we could obtain higher signals with Nus-GPI protein than with GPI protein in all samples. The peak RU values for joint fluids from 5 $\mathrm{RA}$ and $5 \mathrm{OA}$ patients were shown in Table 1. The average $R U$ values for $R A$ and $O A$ were 208.4 and 61.4 with the use of Nus-GPI and 104.3 and 38.8 with GPI, respectively. The signals from joint fluids of RA patients were significantly higher than the signals from those of $O A$ patients when either NusA-GPI or GPI protein was used for the assay $(P<0.005$ for NusA-GPI and $P<0.0001$ for GPI, $t$ test). Furthermore, we could confirm that the binding substance to the GPI fusion proteins were antibodies by injecting anti-human immunoglobulin antibody after the binding of joint fluids to immobilized proteins (Figure 4C).
These data indicated that recombinant GPI and Nus-GPI proteins could be effectively used to detect anti-GPI Abs in RA patients.

\section{Discussion}

This report describes an SPR-based assay to detect autoantibodies in the joint fluids of RA patients. The SPR assay has several advantages over other methods in the detection of autoantibodies. First, radiolabeling or other kinds of labeling is not required for detection because the measured parameter is a refractory index change, i.e. a physical quantity detected by a SPR biosensor (Schuck, 1997). The SPR biosensors can detect specific reversible binding of a reactant in a solution to a binding partner immobilized on the surface of the sensor and allow the real-time detection and monitoring (Schuck, 1997). Secondly, a very small amount of sample (about several microliters) is needed for a single assay. We used a 1:100 diluted samples for the assay. Thirdly, the assay is very rapid and we could obtain results in real time. However, this assay was not efficient for a simultaneous assay of multiple samples since Biacore 2000 machine has only a single line of flow and four flow cells. Each patient's samples were applied after previous samples were assayed and the cells were washed and regenerated. In contrast, the SPR assay would be very advantageous for the detection of multiple kinds of antibodies from the same patient when the SPR device with multiple flow cells is available 
in future. With autoantigen panels, we will be able to make a diagnosis of autoimmune diseases based on the presence of different kinds of autoantibodies which bind different sets of autoantigens (Hueber et al., 2002).

Availability of purified or recombinant autoantigens is essential for the SPR assay. In this study, we produced recombinant proteins from bacteria and tested for the assay. Since many proteins are insoluble and partition into detergent-insoluble fractions in bacterial lysate, recombinant antigens are not available in many cases. Here we tested the usefulness of NusA fusion protein. Since NusA protein is hydrophilic and increases the solubility of fusion protein (Terpe, 2003), recombinant NusA-fused autoantigens may be produced in case that the recombinant autoantigen protein itself is largely insoluble. Next, it is necessary that there is no or little antibodies in normal individuals or autoimmune disease patients which bind NusA. Fortunately, it was shown here that there was a very small binding to the flow cell immobilized with NusA. These results indicate that NusA fusion protein may be efficiently used for the production of many recombinant antigens and the detection of autoantibodies. It would also be very advantageous to be able to overproduce and easily purify GPI. In this study, a simple and rapid preparative protocol for GPI from $E$. coli was employed. While most Nickel affinity chromatography steps use a stepwise elution protocol, our protocol utilized a continuous linear gradient elution and achieved a rapid one-step purification with a high yield $(120 \mathrm{mg} / 1$ liter of culture).

In order to utilize recombinant GPI protein to detect autoantibodies against GPI from RA patients, the recombinant GPI protein should have the same conformation with the natural GPI protein and retain epitopes recognized by autoantibodies present in RA patients. The recombinant GPI protein appears to have the intact conformation of the natural counterpart based on some physical characeristics. First, the recombinant GPI protein was purified as dimers as previously reported (Sun et al., 1999). NusA-GPI protein was purified as tetramers, but since NusA protein itself was produced as dimers, NusA-GPI protein was also presumed to reflect the intact stoichiometry of GPI protein.

Since there was very little binding of joint fluids to NusA, the utilization of NusA fusion proteins are thought to be a good method for the study of autoantibodies when recombinant autoantigen proteins are not soluble in bacterial lysate. We interpreted that NusA fusion protein might provide higher RU values than His-tag fusion protein without NusA because NusA fusion protein is present as dimers and antibodies have a higher avidity to antigens with repeated epitopes. However, NusA fusion protein also detected antibodies in $O A$ patients, which were not detected by the fusion protein without NusA, which suggested that NusA fusion protein might also bind some low-affinity antibodies in $\mathrm{OA}$ patients. In conclusion, it was demonstrated in this study that recombinant NusA-GPI fusion protein could be efficiently used for the detection of autoantibodies against GPI in RA patients using the SPR analysis.

\section{Acknowledgement}

This work was supported by a grant of the Korea Health $21 \mathrm{R}$ \& D Project, Ministry of Health and Welfare, Republic of Korea (01-PJ3-PG6-01GN12-0001).

\section{References}

Altman R, Asch E. Bloch D, Bole G, Borenstein D, Brandt K, Christy W, Cooke TD, Greenwald R, Hochberg M, et al. Development of criteria for the classification and reporting of osteoarthritis. Classification of osteoarthritis of the knee. Diagnostic and Therapeutic Criteria Committee of the American Rheumatism Association. Arthritis Rheum 1986;29:1039-49

Amraei M, Nabi IR. Species specificity of the cytokine function of phosphoglucose isomerase. FEBS Lett 2002;525:151-5

Arnett FC, Edworthy SM, Bloch DA, McShane DJ, Fries JF, Cooper NS, Healey LA, Kaplan SR, Liang MH, Luthra HS, et al. The American Rheumatism Association 1987 revised criteria for the classification of rheumatoid arthritis. Arthritis Rheum 1988;31:315-24

Chaput M, Claes V, Portetelle D, Cludts I, Cravador A, Burny A, Gras H, Tartar A. The neurotrophic factor neuroleukin is $90 \%$ homologous with phosphohexose isomerase. Nature 1988;332:454-5

Faik P, Walker JI, Redmill AA, Morgan MJ. Mouse glucose6 -phosphate isomerase and neuroleukin have identical $3^{\prime}$ sequences. Nature 1988;332:455-7

Gil MC, Lee MH, Seo JI, Choi YL, Kim MK, Jung KC, Park $\mathrm{SH}$, Kim TJ. Characterization and epitope mapping of two monoclonal antibodies against human CD99. Exp Mol Med 2002;34:411-8

Gurney ME, Heinrich SP, Lee MR, Yin HS. Molecular cloning and expression of neuroleukin, a neurotrophic factor for spinal and sensory neurons. Science 1986;234:566-74

Haga A, Niinaka Y, Raz A. Phosphohexose isomerase/autocrine motility factor/neuroleukin/maturation factor is a multifunctional phosphoprotein. Biochim Biophys Acta 2000;1480: 235-44

Hueber W, Utz PJ, Steinman L, Robinson WH. Autoantibody profiling for the study and treatment of autoimmune disease. Arthritis Res 2002;4:290-5

Lernmark A. Autoimmune diseases: are markers ready for prediction? J Clin Invest 2001;108:1091-6

Mandik-Nayak L, Wipke BT, Shih FF, Unanue ER, Allen PM. Despite ubiquitous autoantigen expression, arthritogenic 
autoantibody response initiates in the local lymph node. Proc Natl Acad Sci USA 2002;99:14368-73

Matsumoto I, Maccioni M, Lee DM, Maurice M, Simmons B, Brenner M, Mathis D, Benoist C. How antibodies to a ubiquitous cytoplasmic enzyme may provoke joint-specific autoimmune disease. Nat Immunol 2002;3:360-5

Plotz PH. The autoantibody repertoire: searching for order. Nat Rev Immunol 2003;3:73-8

Robinson WH, DiGennaro C, Hueber W, Haab BB, Kamachi M, Dean EJ, Fournel S, Fong D, Genovese MC, de Vegvar $\mathrm{HE}$, Skriner K, Hirschberg DL, Morris RI, Muller S, Pruijn GJ, van Venrooij WJ, Smolen JS, Brown PO, Steinman L, Utz PJ. Autoantigen microarrays for multiplex characterization of autoantibody responses. Nat Med 2002;8:295-301

Schaller M, Burton DR, Ditzel HJ. Autoantibodies to GPI in rheumatoid arthritis: linkage between an animal model and human disease. Nat Immunol 2001;2:746-53

Schuck $P$. Use of surface plasmon resonance to probe the equilibrium and dynamic aspects of interactions between biological macromolecules. Annu Rev Biophys Biomol Struct 1997;26:41-566
Sun $A Q$, Yuksel KU, Jacobson TM, Gracy RW. Isolation and characterization of human glucose-6-phosphate isomerase isoforms containing two different size subunits. Arch Biochem Biophys 1990;283:120-9

Sun YJ, Chou CC, Chen WS, Wu RT, Meng M, Hsiao CD. The crystal structure of a multifunctional protein: phosphoglucose isomerase/autocrine motility factor/neuroleukin. Proc Natl Acad Sci USA 1999;96:5412-7

Terpe K. Overview of tag protein fusions: from molecular and biochemical fundamentals to commercial systems. Appl Microbiol Biotechnol 2003;60:523-33

van Boekel MA, Vossenaar ER, van den Hoogen $\mathrm{FH}$, van Venrooij WJ. Autoantibody systems in rheumatoid arthritis: specificity, sensitivity and diagnostic value. Arthritis Res 2002; $4: 87-93$

Wipke BT, Wang Z, Kim J, McCarthy TJ, Allen PM. Dynamic visualization of a joint-specific autoimmune response through positron emission tomography. Nat Immunol 2002;3:366-72

Xu W, Lee P, Beutler E. Human glucose phosphate isomerase: exon mapping and gene structure. Genomics 1995;29: $732-9$ 